\title{
The Effect of Posted Speed Limit on the Dispersion of Traffic Flow Speed
}

\author{
Chao Gao ${ }^{1} \mathbb{D}$, Jinliang $\mathrm{Xu}^{1, *}$, Qunshan $\mathrm{Li}^{2}$ and Jie Yang ${ }^{1}$ \\ 1 School of Highway, Chang'an University, Xi'an 710064, China \\ 2 Qinghai Province Traffic Construction Project Cost Management Station, Xining, Qinghai 810003, China \\ * Correspondence: xujinliang@chd.edu.cn
}

Received: 10 June 2019; Accepted: 26 June 2019; Published: 29 June 2019

\begin{abstract}
Speed dispersion is an important indicator to portray the quality of traffic flow and is closely related to the road safety operation level. In order to clarify the influence of posted speed limits on the dispersion of traffic flow speed, three sections with speed limits of $80 \mathrm{~km} / \mathrm{h}, 100 \mathrm{~km} / \mathrm{h}$ and $120 \mathrm{~km} / \mathrm{h}$ on the same expressway were selected for observation, and traffic volume, speed and other parameters were collected. The characteristic speeds, such as average speed, $\mathrm{V}_{15}$ and $V_{85}$, were evaluation indicators, where $V_{15}$ and $V_{85}$ are the speeds of the 15th and 85th percentiles measured at the feature points of the road when the traffic is in a free-flow state and the weather is good. The relationship between different posted speed limit values and the above indicators was analyzed using the statistical analysis software, SPSS. The results show that the speed limit has a high correlation with the average speed of traffic flow, $\mathrm{V}_{15}$ and $\mathrm{V}_{85}$ in free-flow state, with the coefficient of determination being as high as $0.84,0.85$ and 0.92 , respectively. In the restricted flow state, the factors affecting the driver's driving speed are mainly the decrease in driving freedom caused by the increase of traffic volume rather than the speed limit value. In a free-flow state, when the posted speed limit is increased and the average speed and the $\mathrm{V}_{85}$ also increased by approximately the same magnitude. The posted speed limit values of $80 \mathrm{~km} / \mathrm{h}, 100 \mathrm{~km} / \mathrm{h}$ and $120 \mathrm{~km} / \mathrm{h}$ correspond to the 90,88 and 97 percentile speeds of the traffic flow, respectively. The higher the speed limit is, the larger the speed difference between $\mathrm{V}_{15}$ and $\mathrm{V}_{85}$ becomes. The results of the study are very useful for rationally determining the speed limit scheme under different traffic flows.
\end{abstract}

Keywords: speed dispersion; posted speed limit; traffic flow; expressway

\section{Introduction}

The discreteness of traffic flow speed can reflect the quality of traffic flow and is an important concept in the field of traffic engineering. A number of factors have been found to increase the dispersion of traffic flow speeds, including posted speed limits, intersections, on-street parking, pedestrian activity and the composition of traffic flow. However, data constraints or insufficient samples prevent most of the research conclusions on the subject from being widely accepted. China's understanding of the discreteness of traffic speed caused by speed limits is not comprehensive. Relevant researches in developed countries mainly focus on the relationship between design speed, operating speed and posted speed limit and have revealed some fully demonstrated results and conclusions that are generally accepted. For example, relationship models between posted speed limit, operating speed, design speed are established. Dixon et al. [1] selected multiple fixed observation sites in multi-lane highways, increased the posted speed limit of these locations from $55 \mathrm{mph}(88.6 \mathrm{~km} / \mathrm{h})$ to $65 \mathrm{mph}$ $(104.7 \mathrm{~km} / \mathrm{h})$ and collected the velocity data before and after the posted speed limit change. The study found that when the speed limit is increased, the speed of the free-flow state increases. From the data collected by Parker [2] for an FHWA (Federal Highway Administration) study, it can be determined 
that the average speed, the standard deviation of the speed and the 85th percentile speed differ by less than $2 \mathrm{mph}(3.2 \mathrm{~km} / \mathrm{h})$ before and after the speed limit change. Fitzpatrick surveyed 128 speed limit intervals and found that the speeds of the 85th percentiles were all higher than the speed limit and the speeds of the 50th percentiles were close to the speed limit [3].Fitzpatrick also pointed out that the 85th speed should only be used as the benchmark for the speed limit. The actual speed limit should be $8 \sim 12$ mile/h lower than the 85th speed [4] and based on the statistical data, a linear regression equation of the operating speed and the posted speed limit is established [5]. Burritt [6], Dart et al. [7] found that as the posted speed limit decreases, the average running speed also decreases; Ossiander et al [8], Jernigan et al [9], Freedman and Esterlitz [10], Brow et al [11] and Upchurch [12] found that with a national maximum speed limit from $55 \mathrm{mph}$ to $65 \mathrm{mph}$, the average speed increased by 2-7 $\mathrm{mph}$.

The above conclusions and results illustrate from different perspectives that speed limit changes will have different effects on the speed of traffic flow. When the speed limit value changes by a certain amount, the running speed will increase or decrease correspondingly in a certain proportion. At the same time, the speed differences will also change as the speed limit value changes. Both speed and speed difference are closely related to the degree of dispersion of the vehicle speed.

Vehicle speed dispersion is one of the concerns of speed research. Solomon (1964) [13] studies the relationship between accident and vehicle speed, driver and vehicle and proposes the concept of vehicle speed dispersion, which is defined as the difference in vehicle speed. Due to the differences in research purposes and research methods, as well as the limitations of data collection and processing methods, scholars have used a variety of vehicle speed distribution characteristics indicators to define vehicle speed dispersion. In the current study, the distribution characteristics of vehicle speed mainly include the sample mean value of the vehicle speed, the sample standard deviation, the sample variance, the coefficient of variation (the ratio of the standard deviation to the mean), the skewness and the peak value. According to the existing research results, it can be shown that the speed limit is closely related to the degree of dispersion of the vehicle speed. Some scholars have collected the traffic flow data before and after the adjustment of NMSL (National Maximum Speed Limit), attempted to reveal the influence of speed limit on the dispersion degree of traffic flow speed through statistical indicators using comparative analysis.Burritt [6], Forester et al [14], Rama [15] and other scholars found that when the posted speed limit is reduced, the dispersion of the running speed distribution decreases. Dart's [7] research found that when the speed limit is reduced, the operating speed of the road decreases and the dispersion of the speed distribution decreases, which is manifested by a decrease in the standard deviation of the sample. Garber and Gadiraju [16] pointed out that the sample variance of the running speed decreases with the increase of the speed limit. Some scholars believe that after the speed limit standard is increased, the sample variance of the running speed has not changed significantly. Kockelman [17] collected 1766 speed data from radar guns in Austin, studying the effects of speed limits on speed and standard deviation of speed. This analysis demonstrated that the impact of speed limits on vehicle speed variances is very small. It can be found that there are great differences, even contradictions among the research conclusions.

Chinese scholars have also carried out a lot of research on the influence of speed limit on vehicle speed. The researches mainly focus on the relationship between linear conditions, traffic flow conditions, driving safety line of sight and speed limit [18-21]. Pei et al [18] determined speed limit value of the curve segment and the slope segment through regression statistical analysis, in their research, the data were acquired based on field data and passenger vehicle was selected as standard vehicle form. Cheng Guozhu [19] analyzed the characteristics of expressway speed and established a calculation model based on the maximum speed of the vehicle with the lowest generalized cost. A mathematical method was used to obtain the optimal maximum speed limit reference value of the expressway with different design speeds and different vehicle conditions. These research results provide a certain theoretical accumulation for the study of speed limits in China. However, due to the lack of systematic research on the data before and after the posted speed limit change, in order to study the quantitative change of the characteristic velocity of the traffic flow, the research method 
mostly adopts parallel alignment of different roads. Lijing Wang et al. [20] investigated the speed of seven expressways and analyzed the distribution characteristics of the straight segments, slope section, curved and slope section and curve section under different speed limit schemes, which proved that the speed limit is an important factor affecting the running speed. In terms of the effect of speed limit on vehicle speed dispersion, Wang Hao [21] conducted a comparative analysis of traffic flow data of three different speed-limiting highways in China and Netherlands and used speed standard deviation and speed variation coefficient to characterize vehicle speed dispersion. The speed standard deviation increased with the increase of traffic flow speed and the speed variation coefficient decreased with the increase of traffic flow speed.

Above all, scholars have studied the relationship between speed limit, design speed and operating speed but the purpose of these studies is to use the relationship between them to design and construct an expressway that meets speed expectations. There is still a lack of systematic and in-depth discussion on the effects of vehicle speed dispersion. Although some studies have been conducted, there are no convincing conclusions due to the small number and the consistency of the research samples, in particular, only the velocity variance is used to characterize the speed dispersion, which cannot fully explain the negative impact of vehicle speed distribution on traffic flow. Therefore, this paper intends to select three sections on the expressway with the same vertical slope, flat curve radius and cross section and collect traffic flow data at these three sections with posted speed limit of $80 \mathrm{~km} / \mathrm{h}, 100 \mathrm{~km} / \mathrm{h}$ and $120 \mathrm{~km} / \mathrm{h}$. The vehicle speed and traffic volume data of the traffic flow using a sufficient sample size under the speed value are analyzed, using statistical methods to discover the relationship between the speed limit and the characteristic speed of the traffic flow and confirm if the influence of the speed limit on the traffic flow quality is clearly determined.

\section{Methods}

In order to ensure the consistency of the observed samples, a field survey is used to establish the relationship model between the speed limit and the dispersion of traffic flow speed. The survey needs to eliminate the influence of road conditions. During the survey, it is necessary to control the survey with the same traffic flow at each observation point.

\subsection{Test Condition Control}

The following basic requirements were met when the test sections and observation points are arranged, in order to eliminate the influence of factors other than the posted speed limit on the observation results:

Road sections such as long longitudinal slopes, sharp bends, construction areas, ramp entrances, bridges and tunnel structures were avoided; two types of upper limit speed values were included and the speed limit area was no less than $2 \mathrm{~km}$; the speed limit sign was clearly visible, with no occlusion; the position of the observation point was positioned $800 \mathrm{~m}$ after the speed limit sign, which was determined based on the short-term memory characteristics of the driver. The purpose of these requirements was to ensure that the observation speed is the result of the "speed limit" effect; the climatic conditions are ideal when observed.

In accordance to all the above requirements, the national expressway G65 straight section K900+000 $\sim$ K912 +000 was selected for observation. Figure 1 shows the details of each observation point. 


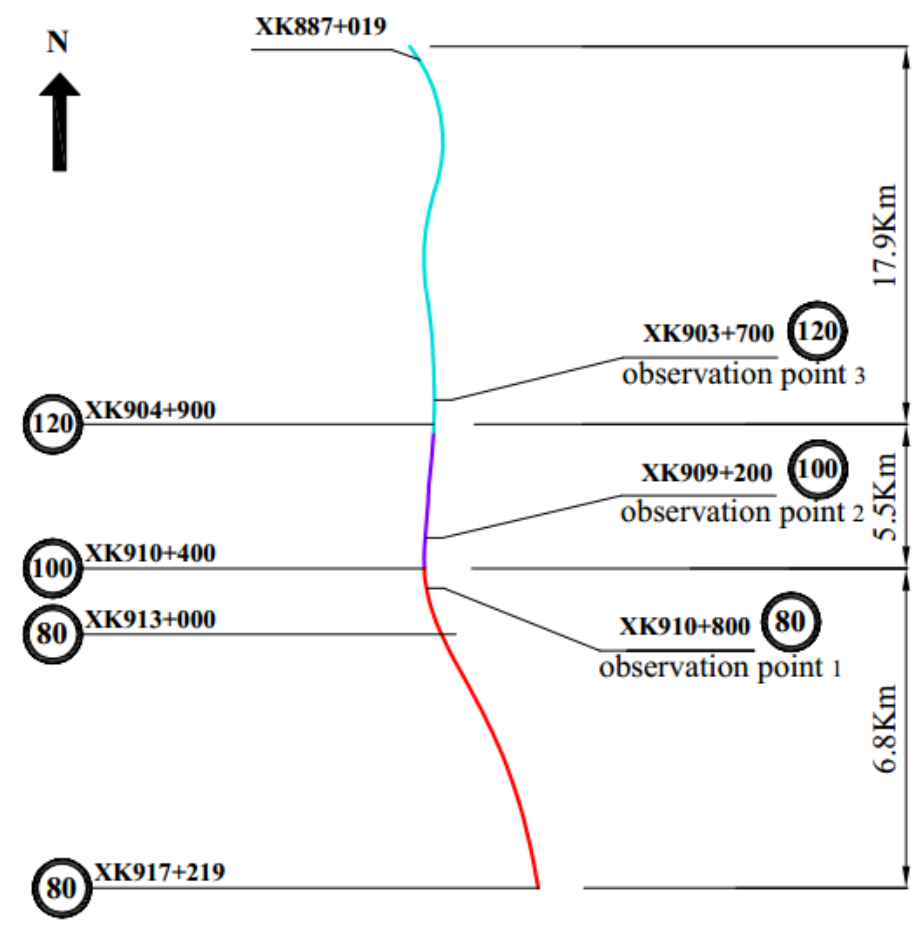

Figure 1. Distribution of observation points.

\subsection{Test Process}

The essential of the field experiments is to ensure that the traffic flow collected at the three observation points is basically the same. Therefore, the start and end of the traffic flow data collection at each observation point are controlled by the same characteristic vehicle. When selecting a characteristic vehicle in the traffic flow, ensure that the vehicle is easily and quickly discovered. Figure 2 shows the basic flow of each group of traffic flow tests. Through the above test process control, it is essentially ensured that the vehicles at each observation point are the same traffic flow.

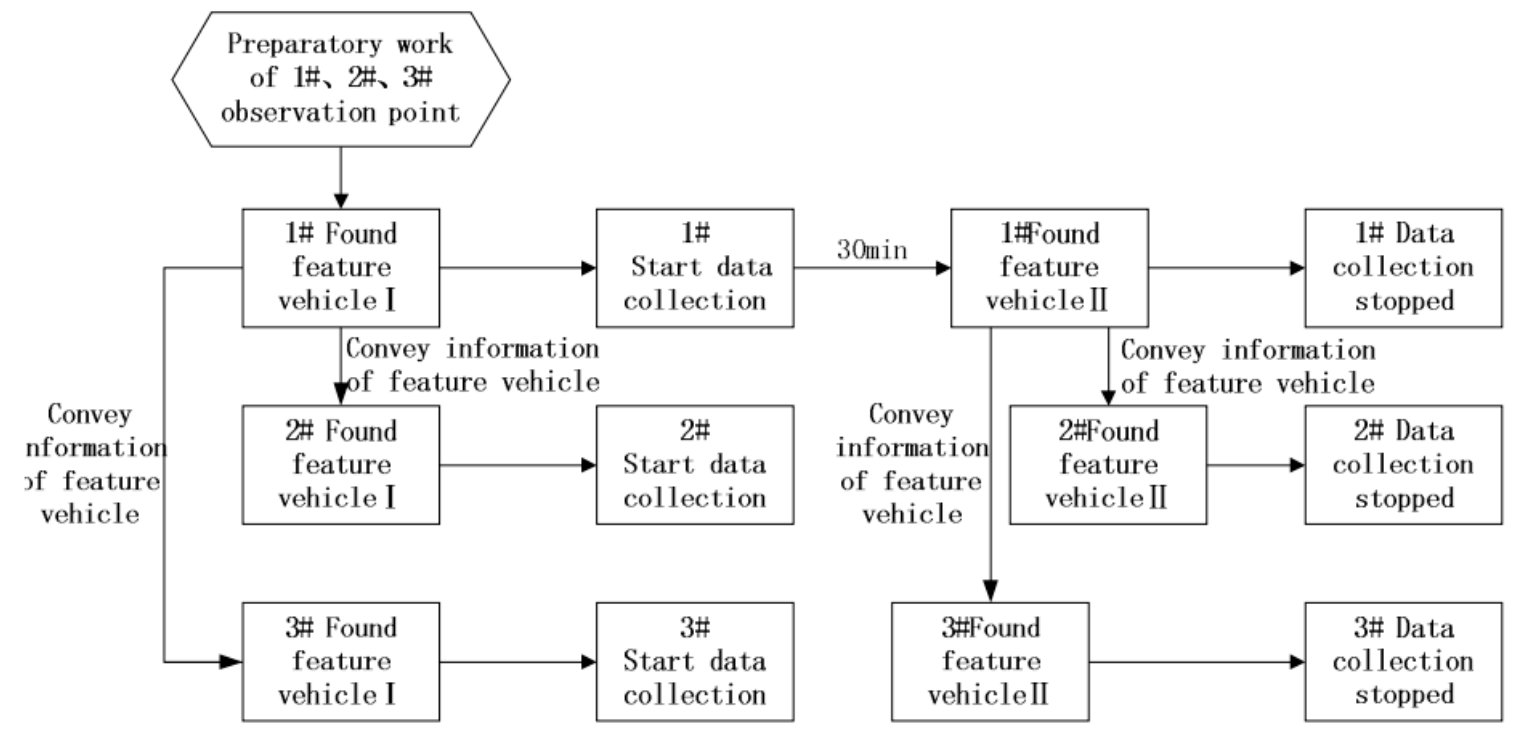

Figure 2. Test flow chart.

The data collection time is from 8:30 am to 6:00 pm and the experiments time is from September 20, 2018 to October 7, 2018, for a total of 18 days, including working days and non-working days and holidays. In each set of traffic flow surveys, the minimum number of vehicles required at each 
observation point is greater than 320 . After the data collection was completed, 150 sets of data were obtained, totaling more than 228,000 vehicles.

At the same time, in order to avoid the influence of observers on driving behavior, laser-type portable roadside traffic survey instruments were used at the observation points to collect cross-section traffic flow data such as volume, speed, vehicle type and headway distance.

\subsection{Data Preprocessing}

In order to ensure the accuracy of survey data, each group of observation samples is subjected to characteristic vehicle comparison checks, to ensure that the same traffic flow is collected by each of the three observation points of each sample and the observation samples with inconsistent characteristic vehicles are discarded. When all test group samples are reliable, SPSS was used to analyze the survey data results. For the analysis, outlier data in the samples, such as the driver's deceleration when driving in the emergency lane and speed while drivers answered mobile phones, were discarded. Finally, 105 sets of valid data were obtained, totaling more than 152,000 vehicles.

\section{Results}

In addition to the influence of posted limited speed (PSL), the vehicle running speed is also affected by traffic volume. The close relationship between volume-velocity indicates that traffic volume has an impact on traffic flow speed. Therefore, when analyzing the impact of speed limit on the vehicle speed distribution, the traffic volume of the road must be considered. Based on the analysis of the variation law of the characteristic speed with different posted speed limit under different traffic flow patterns, the relationship between the posted speed limit and the characteristic speed is found out and then the relationship model between them is established. The ratio $\mathrm{v} / \mathrm{C}$ is used to describe the flow patterns of expressway, it is the ratio of the maximum service traffic volume to the basic traffic capacity. There are important differences in the design speed, number of lanes, traffic composition and other factors of road sections. The " $\mathrm{v}$ " in $\mathrm{v} / \mathrm{C}$ is an objective reflection of actual traffic flow, while " $\mathrm{C}$ " accounts for modifications of the above factors. Its calculation formula is as follows [22]:

$$
v / C=\frac{v}{C_{B} \times f_{W} \times f_{H V} \times f_{P}}
$$

where $v$ is the traffic volume on the road, $\mathrm{pcu} /(\mathrm{h} \cdot \ln ) ; C_{B}$ is the capacity volume of the road, $\mathrm{pcu} /(\mathrm{h} \cdot \ln )$; $f_{W}, f_{H V}, f_{P}$ are correction factors.

According to the Technical Standards for Highway Engineering of China [23], when v/C is less than 0.55 , the traffic flow belongs to free flow and when $\mathrm{v} / \mathrm{C}$ is greater than 0.55 , the traffic flow belongs to the restricted flow. According to the field test data, 69 sets of data of free flow state (v/C less than $0.55)$ and 36 sets of data of non-free flow state (v/C greater than 0.55$)$ were obtained.

The average sample speed of the vehicle speed, that is, the average speed, represents the overall level of the traffic flow on the road segment. Figure 3 shows the average speed $\bar{V}_{T}$ with the change of $\mathrm{v} / \mathrm{C}$ under different posted speed limit. The average speeds of traffic flow are all negatively correlated with the degree of road congestion $\mathrm{v} / \mathrm{C}$ and reveals that the slopes of the three trend lines are roughly the same. The increase of the intercept is basically the same as the increase of the speed limit. For every $20 \mathrm{~km} / \mathrm{h}$ increase in the speed limit, the average speed is increased by about $18 \mathrm{~km} / \mathrm{h}$, which is generally consistent with the increase of the speed limit value. It can be inferred that the average speed of the traffic flow has a high correlation with the speed limit. 


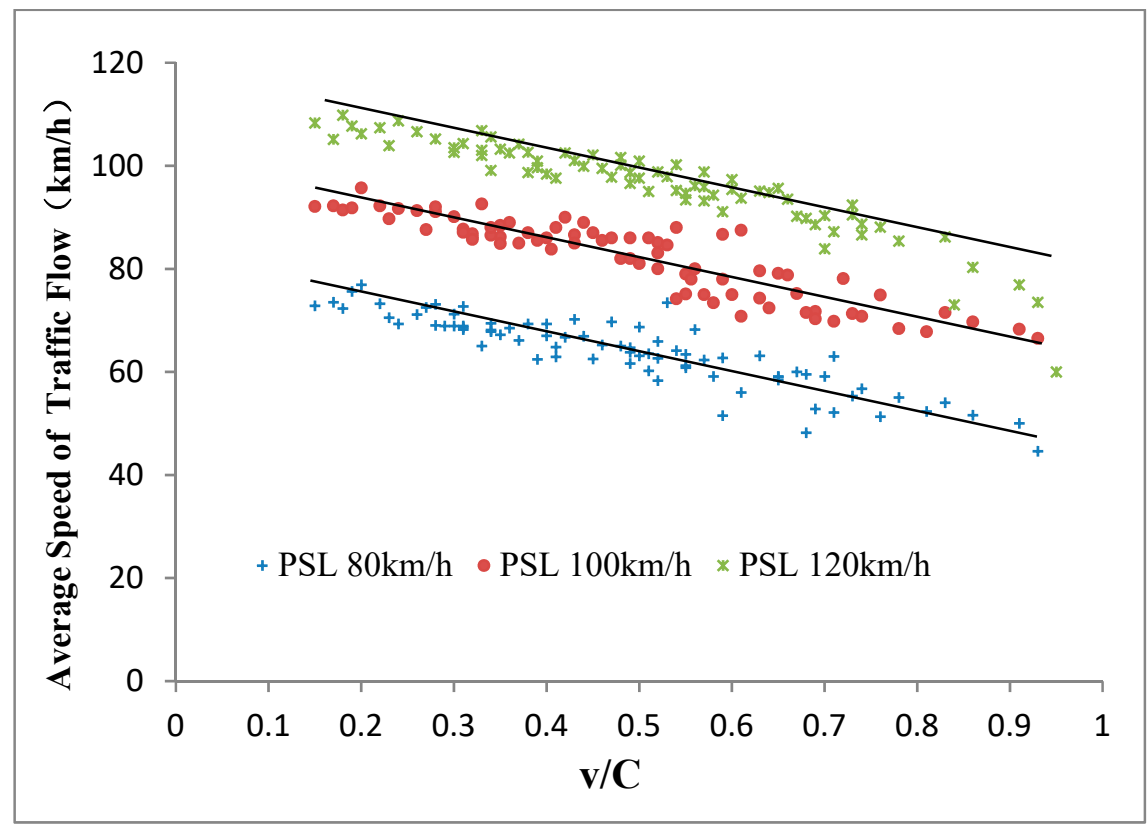

Figure 3. The average speed of traffic flow varies with v/C.

In order to verify the hypothesis, the test data groups were segmented for regression analysis and model verification. In general, approximately $70 \%$ of data is used for model developments and the remaining $30 \%$ data are used to validate the goodness of the model. Therefore, the $\mathrm{v} / \mathrm{C}$ ratios collected during the test are sorted from small to large and test groups with a multiple of 3 were used for model validation and the remaining serial numbers were used for regression analysis. According to statistical principle, under the premise that the confidence level is $95 \%$, the sample size can reach the accuracy requirement of regression analysis when it reaches 43 . Thus, 70 sets of test data were used for regression analysis and the remaining 35 sets of test data were used for model validation.

The 70 sets of test data $\mathrm{v} / \mathrm{C}$ used for regression analysis were divided into groups of 0.05 units and the average running speed of each group was obtained. Figure 4 is a scatter plot of the relationship between the average speed $\bar{V}_{T}$ and the PSL value. It is found that there is a certain relationship between the average speed of the traffic flow and the PSL value, the relationship model between the average speed and the PSL is established by a regression:

$$
\bar{V}_{T}=0.942 P S L-9.0618 \quad R^{2}=0.8352
$$

where: $\bar{V}_{T}$ indicates the average speed, $P S L$ indicates the posted speed limit value, $80 \mathrm{~km} / \mathrm{h} \leq P S L \leq$ $120 \mathrm{~km} / \mathrm{h}$.

It can be seen from the Formula (2) that the PSL has a significant effect on $\bar{V}_{T}$ : when the PSL value is in the range of $80 \sim 120 \mathrm{~km} / \mathrm{h}$, the average speed changes linearly with the change of the PSL and the fitting coefficient of the model up to 0.8352 and the average speed value is lower than the PSL.

Although the model has a fitting factor of about 0.84 , the model is validated by using the remaining 35 sets of experimental data to further verify the accuracy of the model. The verification results are shown in Figure 5. As shown in Figure 5, the relative errors of the models are all below $10 \%$ and most of them are below $5 \%$ under the free flow state $(\mathrm{v} / \mathrm{C} \leq 0.55)$. Considering the different driver characteristics, the accuracy of the model is high. In addition, when the $\mathrm{v} / \mathrm{C}$ ratio is greater than 0.55 , the relative error of the model is greater than $10 \%$ and the highest error is close to $30 \%$, which indicates that the accuracy of the model under non-free flow is not high. The reason for the analysis is that the traffic flow density is gradually increased and the driving freedom is greatly affected. At this time, the factors affecting the driver's driving speed change are mainly the changes of the external environment rather than the speed limit value. 


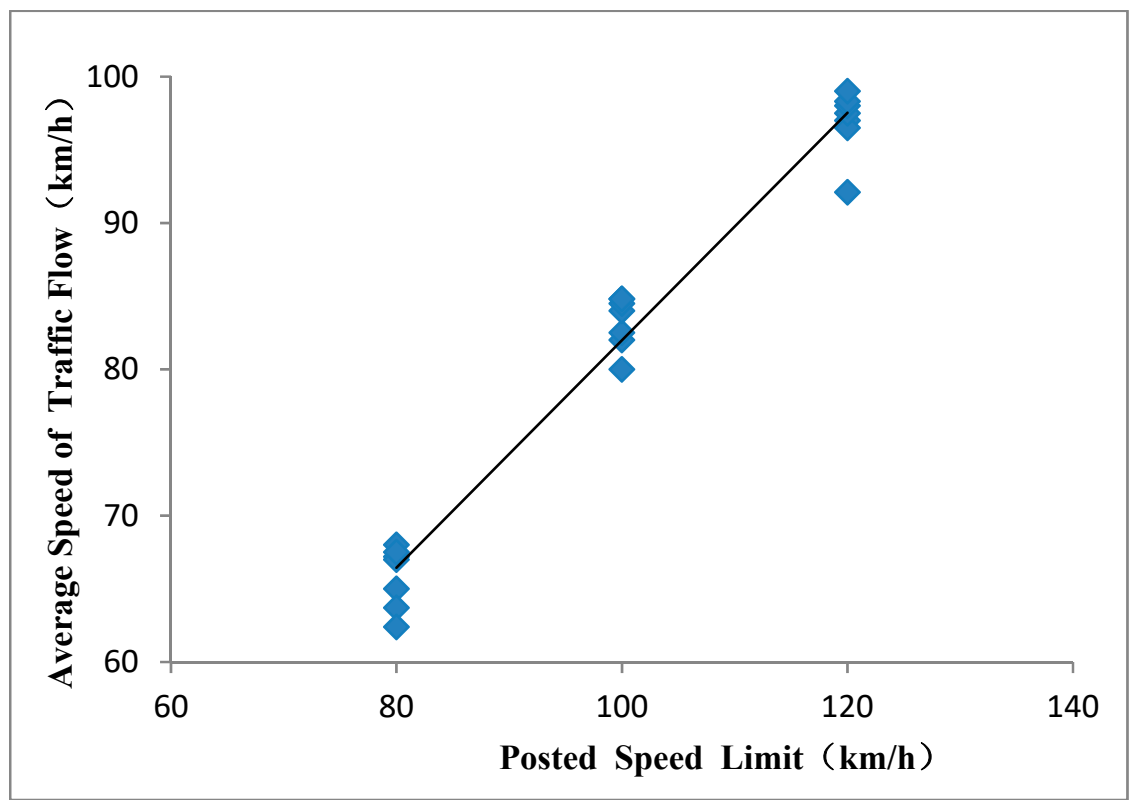

Figure 4. The average speed of traffic flow-posted speed limit (PSL) relationship model.

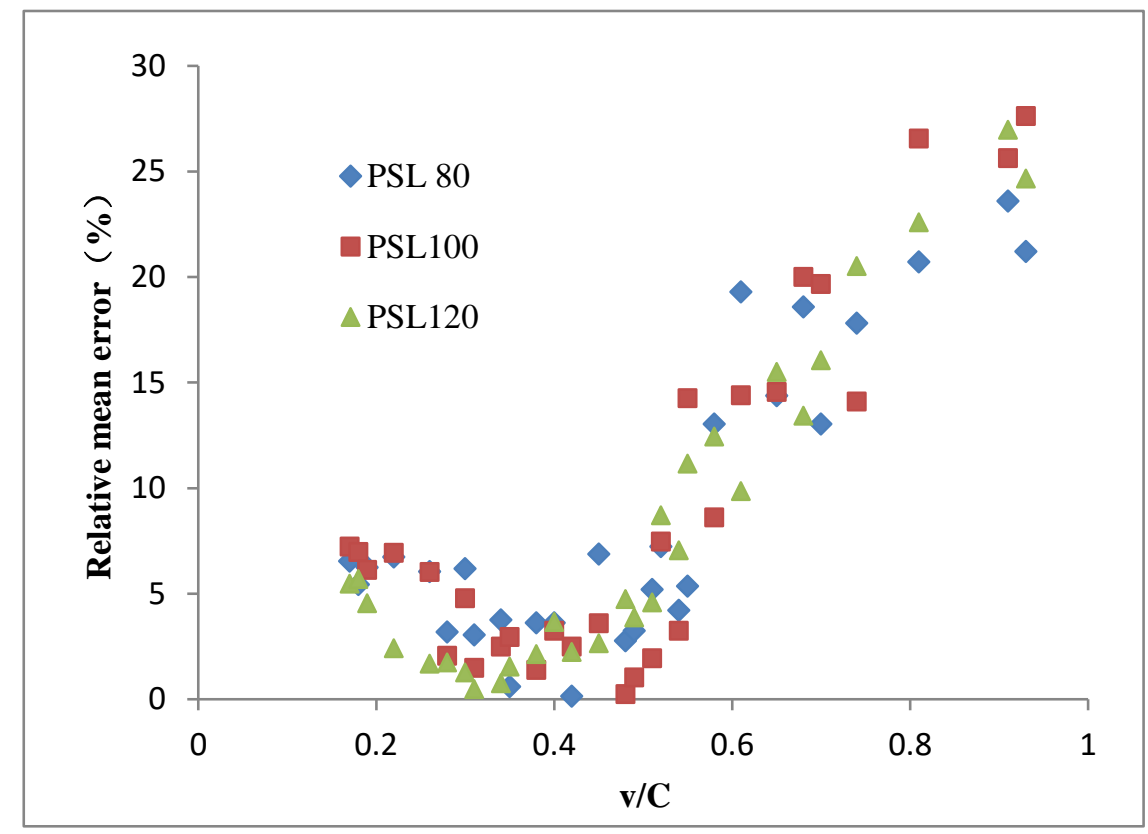

Figure 5. Accuracy test of average speed prediction model.

On the cumulative frequency distribution curve of the running speed, the running speed corresponding to $\mathrm{K} \%$ is called the Kth percentile speed. The slope of the cumulative frequency distribution curve is generally abruptly changed around the 85th and 15th positions, indicating that the proportion of vehicles exceeding the 85 th and less than the 15 th is very small. The $85 \%$ running speed is generally used as a reference for formulating the design speed and the basis for determining the maximum speed limit and the $15 \%$ vehicle speed is used as the basis for determining the minimum speed limit of the expressway. Generally, the vehicle speed of the 85th percentile of all types of cars in the free traffic flow state is used as the characteristic index of the operating speed.

Figure 6 is the speed cumulative frequency curve under each $P S L$ value. The $80 \mathrm{~km} / \mathrm{h}, 100 \mathrm{~km} / \mathrm{h}$ and $120 \mathrm{~km} / \mathrm{h}$ respectively correspond to the 90,88 and 97 division speeds of the traffic flow. The PSL value becomes larger and the characteristic speeds such as $\mathrm{V}_{15}, \mathrm{~V}_{50}$ and $\mathrm{V}_{85}$ are correspondingly larger, 
which also indicates that there is a certain change relationship between the speed characteristic speed and the PSL.

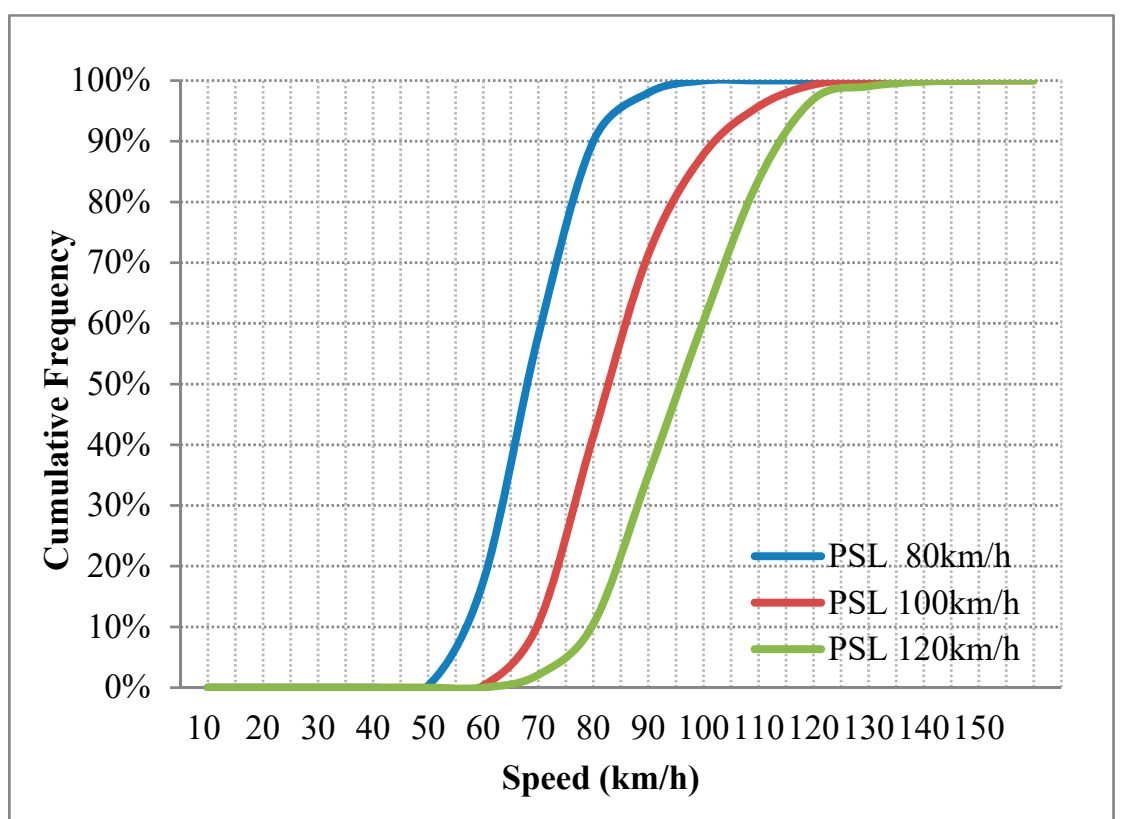

Figure 6. The Cumulative Frequency Distribution Curve of Running Speed.

Similarly, according to the method of the previous analysis, the 69 sets data obtained in the free-flow states are grouped, 46 sets of test data were used for regression analysis. The study divided the $\mathrm{v} / \mathrm{C}$ ratio by 0.05 steps to calculate the $\mathrm{V}_{85}$ and $\mathrm{V}_{15}$ speeds of each step. Figure 7 shows the relationship between $V_{85}$ and $V_{15}$ and the PSL. Established relationship models between $V_{85}, V_{15}$ and PSL values:

$$
\begin{array}{ll}
V_{85}=1.025 P S L-6.7022 & \mathrm{R}^{2}=0.922 \\
V_{15}=0.684 P S L+4.456 & \mathrm{R}^{2}=0.853
\end{array}
$$

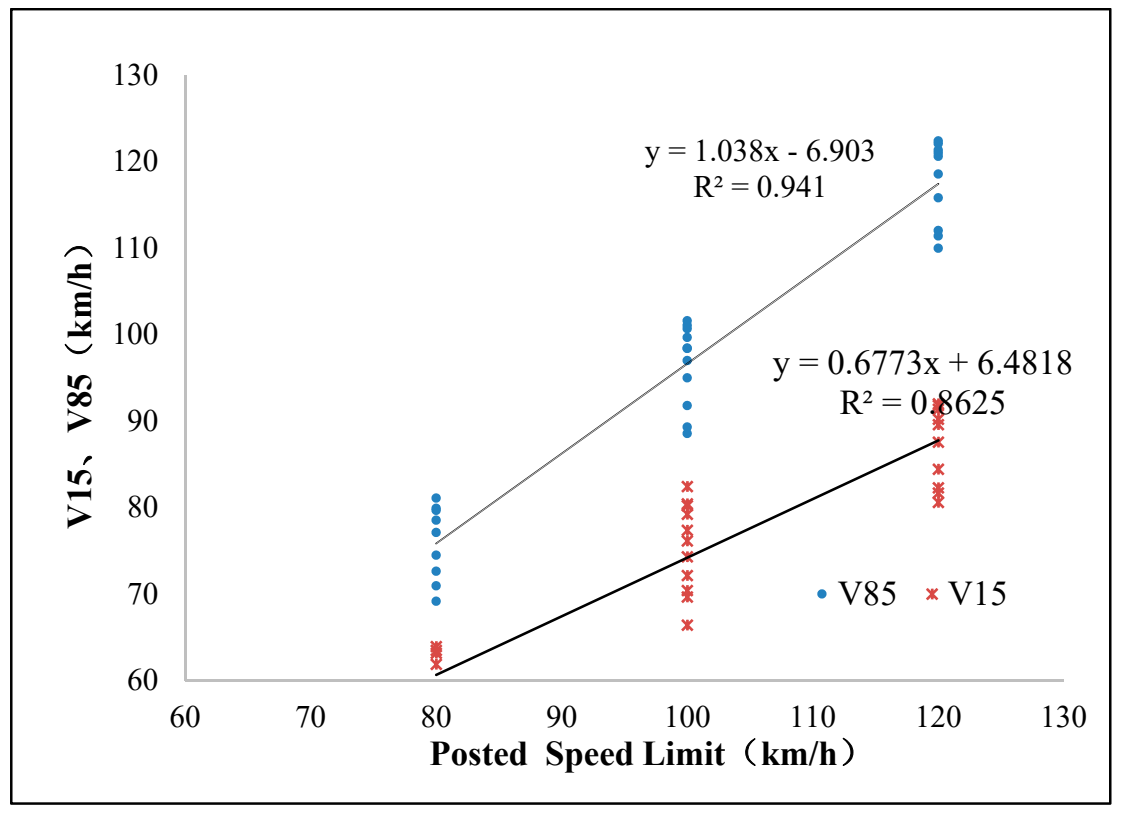

Figure 7. Scatter plot of $\mathrm{V}_{85}, \mathrm{~V}_{15}$ and PSL. 
The results of this study differ from those of scholar Fitzpatrick. Fitzpatrick [5] proposed a model for predicting the operating speed of all highways, with the operating speed regression equation EV85 $=7.657+0.98$ PSL. It can be found that in developed countries such as the United States, the operating speed is higher than the speed limit, while the operating speed in China is lower than the speed limit and the difference between the two is about $10 \mathrm{~km} / \mathrm{h}$. This situation is due to the fact that high speed is generally considered to have an important impact on the full utilization of highway traffic efficiency. However, China's speed limit value has a greater constraint on vehicle travel, resulting in many highways failing to fully meet their potential functions.

To further verify the accuracy of the model, models (3) and (4) were validated using the remaining 23 sets of data. The verification results are shown in Figure 8. It can be clearly seen in Figure 8 that under the free flow state $(\mathrm{v} / \mathrm{C} \leq 0.55)$, the relative error value of the model is below $10 \%$. The accuracy of the model is relatively high considering the dispersion of the vehicle speed caused by different driver characteristics.

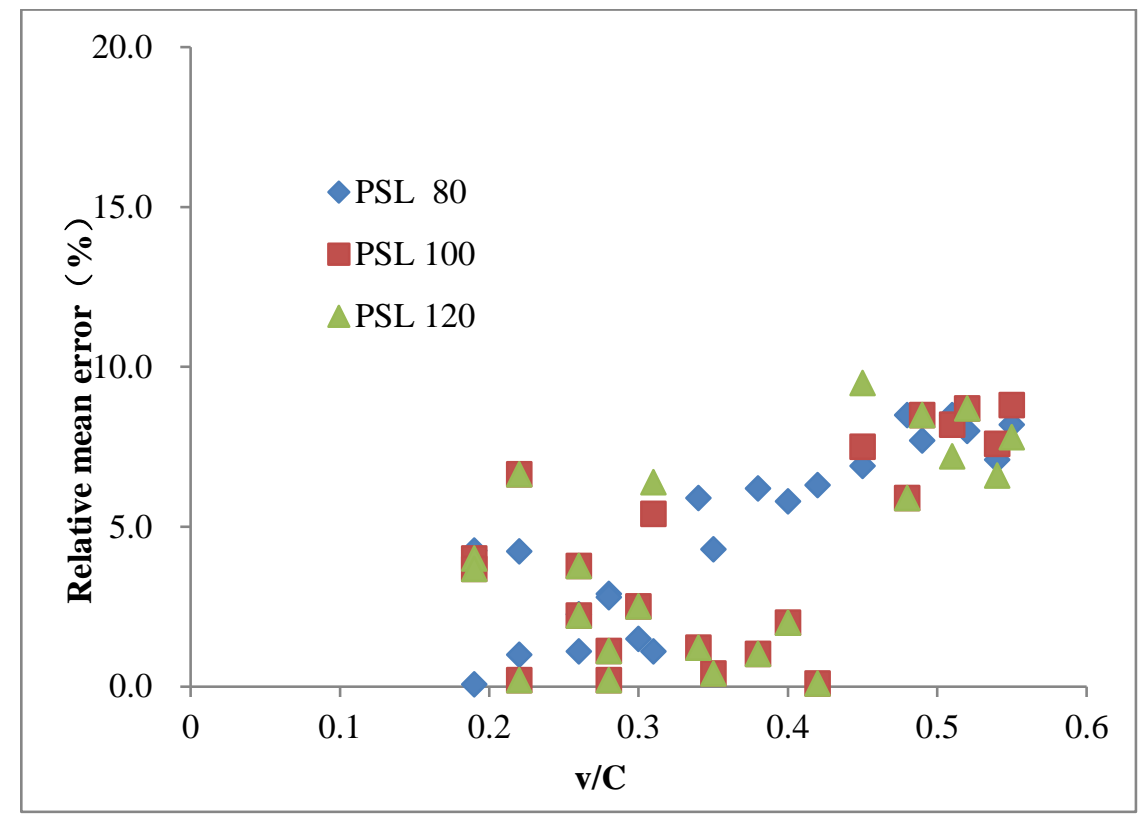

Figure 8. Accuracy test of operating speed prediction model.

In statistics, Range is used to describe the degree of dispersion of a set of data. Range is the difference between the maximum and minimum values of a set of measured values. The larger the range is, the greater the degree of dispersion, conversely, the lesser the degree of dispersion for a smaller range. However, the contingency of the maximum and minimum values in the survey of vehicle speed is too large, so the extreme difference can not reflect the dispersion of vehicle speed very well. There are two commonly used parameters describing the speed distribution, the 85th percentile speed and the 15th percentile speed. Replacing the range with the difference between $V_{85}$ and $V_{15}$ indicates the degree of velocity dispersion, which is more statistically significant, and the error is smaller. If the value $\left|V_{85}-V_{15}\right|$ is larger, it indicates that the more the vehicle speed changes between vehicles, the vehicle speed distribution characteristics can be reflected to some extent.

Figure 9 is a scatter plot of the relationship between the Range and the PSL. It can be seen that, as the PSL increases, the speed dispersion shows an increasing trend and the greater the $P S L$, the larger the value of $\left|V_{85}-V_{15}\right|$.At the same time, it can be seen from Figure 4 that the average speed of traffic flow becomes larger and the speeds of $\mathrm{V}_{15}$ and $\mathrm{V}_{85}$ are both increasing but the rising trend of $\mathrm{V}_{85}$ is greater than $V_{15}$, which leads to an increase in speed dispersion. The main factors causing this gap are vehicles with speed less than $V_{15}$ and vehicles with speed greater than $V_{85}$. The "Technical Standard of Highway Engineering" of China stipulates the dimensions of the design vehicle. In the expressway, 
all models larger than the small passenger car are identified as large vehicles [24]. By analyzing the proportion of large vehicles in the interval less than $\mathrm{V}_{15}$ and the proportion in the interval greater than $V_{85}$, as show in Figure 10, it can be seen that the large vehicle is the largest ratio in the interval of less than $V_{15}$. It is the smallest in the interval where the speed is greater than $V_{85}$ and thus it can be seen that the proportion of the large vehicle gradually decreases as the average speed increases. Or it can be said that in the speed range less than $V_{15}, V_{15}$ is mainly reduced due to the increase of the proportion of large vehicles; in the speed range greater than $V_{85}, V_{85}$ is increased due to the increase of the over-speed ratio of the passenger cars, thus, the value of $\left|V_{85}-V_{15}\right|$ is increased and the degree of dispersion of speed is increased. Therefore, it can be concluded that the two main causes of speed dispersion are vehicles over-speed and large vehicle ratio. Therefore, in order to reduce the speed dispersion of road vehicles and increase the road safety factor, specific measures can be taken from the aspects of improving the over-speed problem and reducing the mixed traffic of large and small vehicles.

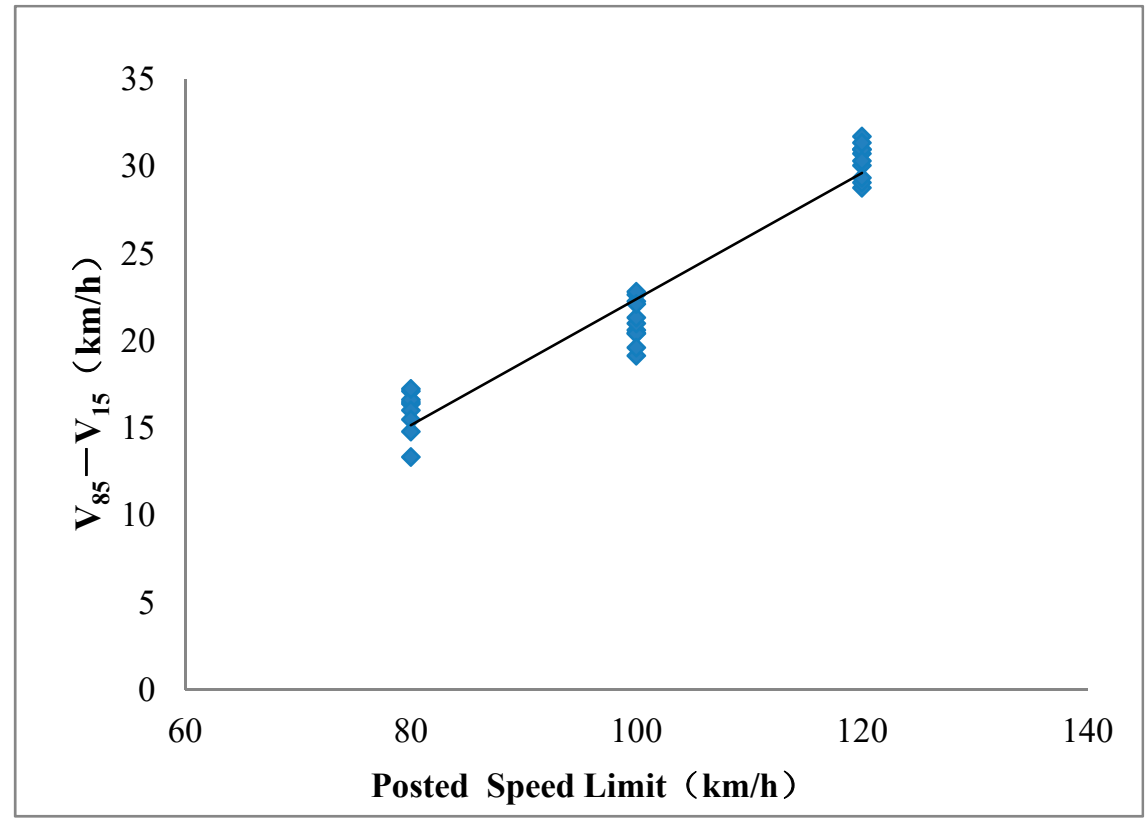

Figure 9. Scatter plot of Range $\left(\mathrm{V}_{85}-\mathrm{V}_{15}\right)$ and PSL.

In addition, the average speed and the vehicle speed range, the vehicle speed sample variance, the sample standard deviation (SD), the coefficient of variation (CV) and the kurtosis also affect and determine the road traffic safety performance. Both the vehicle speed sample variance and the sample standard deviation are measures of the magnitude of the vehicle speed sample fluctuations, reflecting the degree of deviation from the average vehicle speed. The larger the sample variance or sample standard deviation, the greater the fluctuation of the sample data, indicating that the vehicle speed is more discrete.

Figure 11 is the velocity-frequency curve of different speed limits in the free-flow patterns obtained through SPSS analysis. It can be found that all of them are normally distributed. With the increase of the PSL value, the speed of the traffic flow becomes larger; the top of the speed distribution curve at $P S L$ of $80 \mathrm{~km} / \mathrm{h}$ is sharp and the kurtosis is large. The top of the distribution curve at PSL $100 \mathrm{~km} / \mathrm{h}$ and $120 \mathrm{~km} / \mathrm{h}$ gradually becomes lower, the speed limit value increases and the kurtosis of the speed distribution curve decreases. It shows that the speed limit value increases, the speed distribution range becomes wider and the speed becomes discrete. 


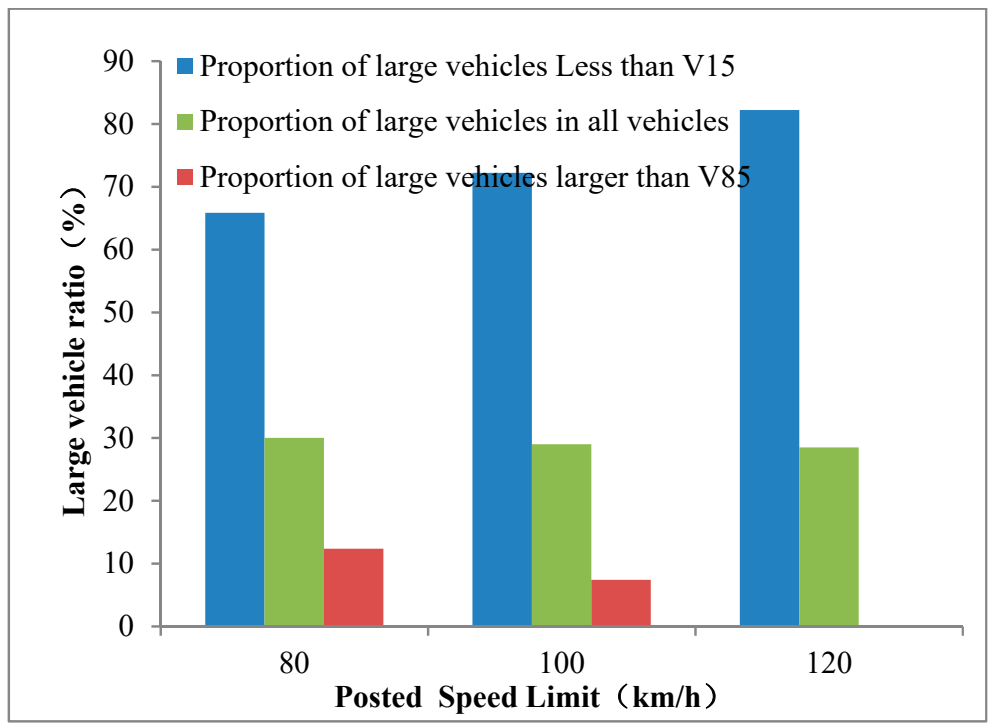

Figure 10. The proportion of the large vehicles in different speed ranges.

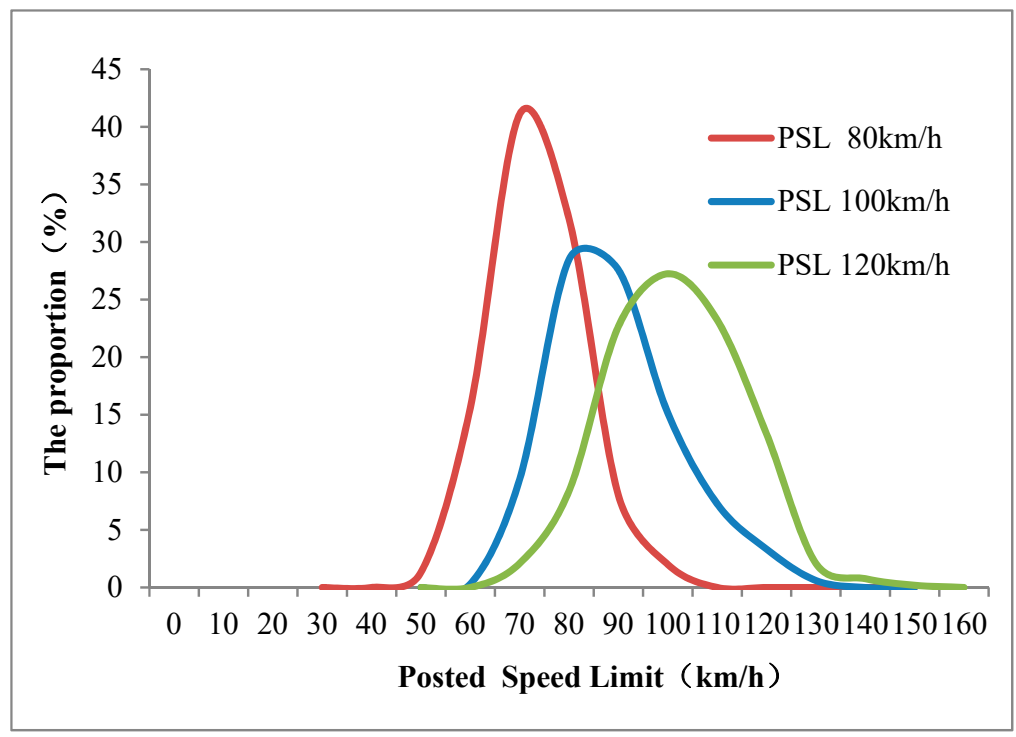

Figure 11. Velocity-Frequency curve.

Standard Deviation (SD), which is most commonly used in probability statistics as a measure of statistical dispersion. The standard deviation is defined as the arithmetic square root of the variance, reflecting the degree of dispersion between individuals within the group. Figure 12 shows that the standard deviation (SD) of the average speed varies with $\mathrm{v} / \mathrm{C}$ under different PSL. It can be clearly reflected that the SD has different degrees of growth with the increase of the PSL. Compared with the survey data with a $P S L$ of $80 \mathrm{~km} / \mathrm{h}$, the standard deviation at a $P S L$ of $100 \mathrm{~km} / \mathrm{h}$ and $120 \mathrm{~km} / \mathrm{h}$ increased by about $5 \mathrm{~km} / \mathrm{h}$ and $7.5 \mathrm{~km} / \mathrm{h}$, respectively. On roads with higher posted speed limits, the SD of traffic flow speed is larger, which indicates that different speed limits have obvious influence on the discrete characteristics of vehicle speed. On the expressway where the PSL is high, the expected vehicle speed distribution range of different vehicles is larger than that of the road section with a lower speed limit, so the degree of speed dispersion is also affected. Under the same PSL, with the increase of traffic volume, the dispersion degree of traffic flow has a slight downward trend. Analyzing the reason for this downward trend it was found that, due to the traffic volume, the vehicle operation was restricted by other vehicles in the traffic flow and the speed and freedom of driving were limited, so the speed dispersion was also affected. 


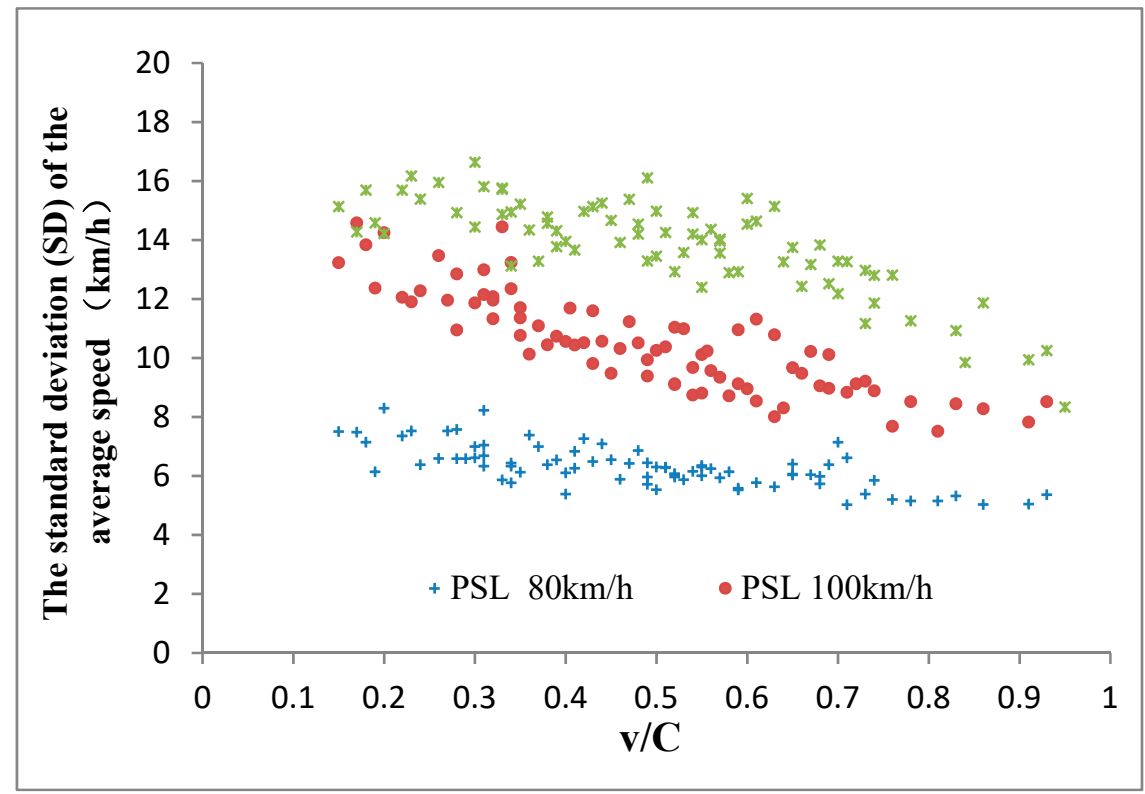

Figure 12. The standard deviation of the average speed varies with v/C.

In order to make the comparison of the speed dispersion of traffic flow under different average speeds more meaningful, the coefficient of variation $(\mathrm{CV})$ is introduced, it is a relative description of vehicle speed dispersion. The coefficient of variation $(\mathrm{CV})$ is the ratio of the standard deviation of the raw data to the average of the original data. Figure 13 depicts the coefficient of variation (CV) for the average speed varies with $\mathrm{v} / \mathrm{C}$ for different speed limits. It can be found that when the posted speed limit is promoted, the $\mathrm{CV}$ is increasing but the effect of traffic volume is not obvious. The $\mathrm{CV}$ for the limit speed of $80 \mathrm{~km} / \mathrm{h}, 100 \mathrm{~km} / \mathrm{h}$ and $120 \mathrm{~km} / \mathrm{h}$ is approximately equal to $0.10,0.13$ and 0.15 times the average speed. This is different from the research results of Leong [24]. When Leong compiled a compilation of speed measurements for three years in Australia's 31 suburban stations, it was found that the CV of the vehicle speed was about 0.17 , the values under different speed limit standards obtained from the survey are smaller than those in developed countries.

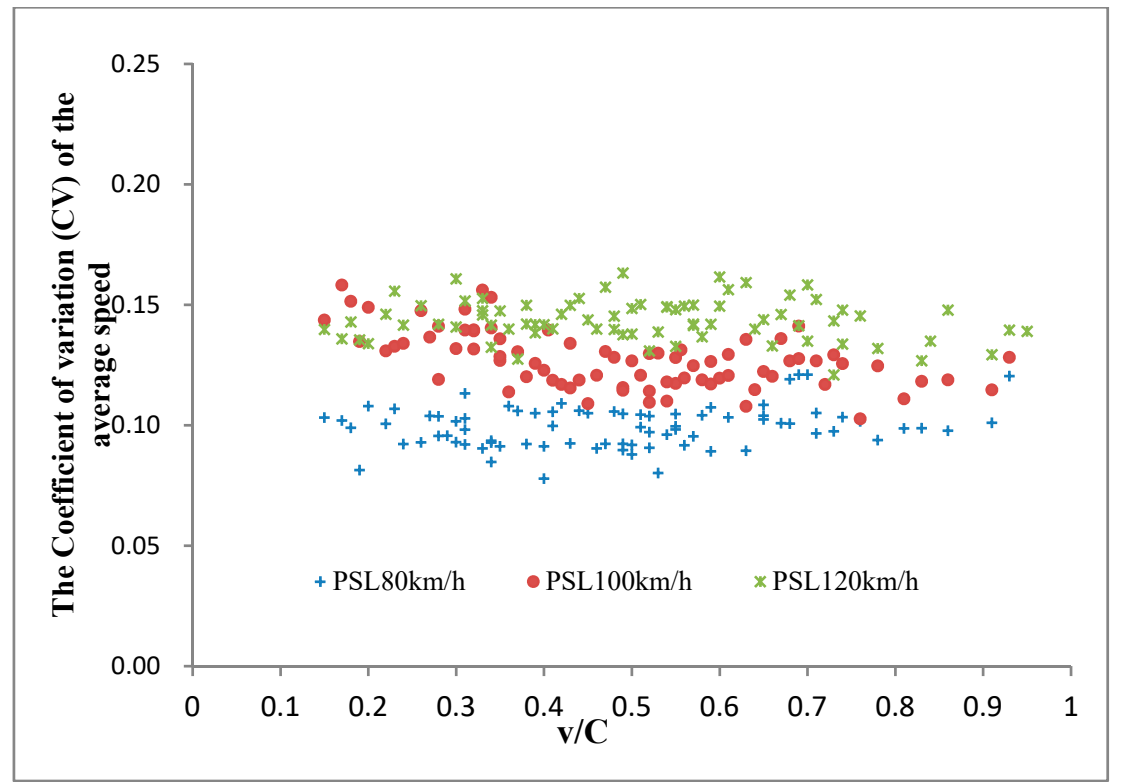

Figure 13. The average speed standard deviation Coefficient of variation $(\mathrm{CV})$ varies with v/C. 
According to the previous analysis, as the PSL increases, the average speed $\bar{V}_{T}$ increases, $\left|V_{85}-V_{15}\right|$ and the SD, CV of the average speed became larger. It can be seen that the dispersion degree of traffic flow speed has a close relationship with the PSL. At the same time, the size of the vehicle speed distribution interval determines the average speed of the vehicle, which in turn affects the dispersion degree of the traffic flow speed. Therefore, it can be concluded that the main action to control the dispersion of road speed is to control the distribution range of vehicle speed.

\section{Conclusions}

In this study, through field experiments, the speed dispersion of the same traffic flow with different speed limits was analyzed. Indicators such as the average speed $\bar{V}_{T}$, the $S D, C V$ of the average speed, the kurtosis of speed frequency curve and the cumulative frequency distribution curve of vehicle speed were selected.

Based on the results obtained, we can conclude that: (1) In free-flow state, the posted speed limit and the average speed of traffic flow, $\mathrm{V}_{15}$ and $\mathrm{V}_{85}$ have a high correlation and the coefficient of determination is as high as $0.84,0.85$ and 0.92 , respectively. As the posted speed limit increases, the average speed and $V_{85}$ will increase by about the same magnitude, the increase of $V_{15}$ speed will be lower than this magnitude. In the restricted flow state, the factors affecting the driver's driving speed are mainly the decrease in driving freedom caused by the increase of traffic volume rather than the speed limit value (2) In a free-flow state, the speed cumulative frequency curve under different posted speed limit standards indicates that the speed limit values of $80 \mathrm{~km} / \mathrm{h}, 100 \mathrm{~km} / \mathrm{h}$ and $120 \mathrm{~km} / \mathrm{h}$, respectively, correspond to the 90,88 and 97 division speeds of the traffic flow. The higher the posted speed limit is, the larger the speed difference between $V_{15}$ and $V_{85}$. The main factor causing this gap is the distribution ratio of the large vehicles and passenger cars in the speed distribution interval and the over-speed ratio of passenger cars. (3) The velocity-frequency curve distribution under different speed limits in the free-flow state shows that as the speed limit value increases, the traffic flow speed becomes larger; the speed limit curve with low speed limit is sharp at the top and the kurtosis is large. The speed curve of the high speed is lower at the top, the kurtosis is reduced. As the speed limit value increased, the speed distribution range is widened and the speed becomes discrete. (4) As the posted speed limit increases, the SD of the average speed increases in varying degrees. Compared with the survey data with posted speed limit of $80 \mathrm{~km} / \mathrm{h}$, the SD of the posted speed limit of $100 \mathrm{~km} / \mathrm{h}$ and $120 \mathrm{~km} / \mathrm{h}$ increased by about $5 \mathrm{~km} / \mathrm{h}$ and $7.5 \mathrm{~km} / \mathrm{h}$, respectively. Under the same posted speed limit, with the increase of traffic volume, the SD slightly decreased. (5) With the increase of the posted speed limit, the CV of the average speed also increases. The CV at the speed limit of $80 \mathrm{~km} / \mathrm{h}, 100 \mathrm{~km} / \mathrm{h}$ and $120 \mathrm{~km} / \mathrm{h}$ are $0.10,0.13$ and 0.15 , respectively. China's CV of the average speed is lower than those in developed countries. At the same time, studies have shown that the effect of traffic volume on the $\mathrm{CV}$ is not obvious. (6) The degree of dispersion of traffic flow speed has a close relationship with the posted speed limit. The main actions to control the dispersion of speed should start with controlling the speed distribution intervals.

The obtained results are very beneficial for the reasonable determination of the speed limit scheme under different traffic flow patterns. However, due to the limitations of road infrastructure conditions, only the traffic flow parameters of the same traffic flow under the three speed limit standards of $80 \mathrm{~km} / \mathrm{h}, 100 \mathrm{~km} / \mathrm{h}$ and $120 \mathrm{~km} / \mathrm{h}$ were collected, the influence of more different speed limit standards on the distribution of traffic flow speed remains to be further studied. Therefore, we will continue to supplement this research in the future and study the impact of different posted speed limits on road safety.

Author Contributions: Conceptualization, J.X.; Data curation, C.G., J.X. and J.Y.; Formal analysis, C.G. and J.Y.; Investigation, C.G.; Methodology, C.G.; Resources, Q.L.; Supervision, J.X.; Writing - original draft, C.G.; Writing review \& editing, J.X. 
Funding: This research was funded by Shandong Provincial Department of Transport Technology Plan (Grant no.2017B50) and Key Science and Technology Projects in the Transport Industry of the Ministry of Transport (Grant no. 2018-ZD1-001, 2018-MS1-001).

Conflicts of Interest: The authors declare no conflict of interest.

\section{References}

1. Dixon, M.P. Evaluation of the Impacts of Reducing Truck Speeds on Interstate Highways in IDAHO; National Institute for Advanced Transportation Technology University of Idaho: Moscow, Idaho, 2000.

2. Parker, M.R. Synthesis of Speed Zoning Practices; Department of Transportation Report FHWA/RD-85/096; Federal Highway Administration: Washington, DC, USA, 1985; p. 8790.

3. Fitzpatrick, K. Design Speed, Operating Speed and Posted Speed Relationships. ITE J. 2003, 67, 5259.

4. Fitzpatrick, K. Is 85th Percentile Speed Used to Set Speed Limits? In Proceedings of the ITE 2002Annual Meeting and Exhibit, Philadelphia, PA, USA, 4 August 2002; p. 3240.

5. Fitzpatrick, K.; Fambro, D. Predicting Operating Speeds on Tangent Sections of Two-Lane Rural Highways. Transp. Res. Rec. 2000, 1737, 50-57. [CrossRef]

6. Burritt, B.E. Analysis of the Relation of Accidents and the 88-km/h (55-mph) Speed Limit on Arizona Highways. Transp. Res. Rec. 1976, 34-35.

7. Dart, O.K. Effects of the $88.5-\mathrm{km} / \mathrm{h}(55-\mathrm{mph})$ speed limit and its enforcement on traffic speeds and accidents. Transp. Res. Rec. 1984, 643, 23-32.

8. Ossiander, E.M.; Cummings, P. Freeway speed limits and traffic fatalities in Washington State. Accid. Anal. Prev. 2002, 34, 13-18. [CrossRef]

9. Lynn, C.W.; Jernigan, J.D. The Impact of the $65 \mathrm{mph}$ Speed Limit on irginia's Rural Interstate Highways Through 1990; Report VTRC 92-R12; Transportation Research Council: Charlottesville, VA, USA, 1992; pp. 213-219.

10. Freedman, M.; Esterlitz, J.R. Effects of the 65-mph speed limit on speeds in three states. Transp. Res. Rec. 1993, 52-61.

11. Brown, D.B.; Maghsoodloo, S.; McArdle, M.E. The safety impact of the $65 \mathrm{mph}$ speed limit: A case study using Alabama accident records. J. Saf. Res. 1993, 125-139. [CrossRef]

12. Upchurch, J. Arizona's experience with the 65-mph speed limit. Transp. Res. Rec. 1989, 1-6.

13. Solomon, D. Accidents on Main Rural Highways Related to Speed, Drivers and Vehicle; Bureau of Public Roads: Washington, DC, USA, 1964.

14. Forester, T.H.; McNown, R.F.; Singell, L.D. A cost-benefit analysis of the $55 \mathrm{mph}$ speed limit. South. Econ. J. 1984, 50, 631-641. [CrossRef]

15. Rama, P. Effects of weather-controlled variable speed limits and warning signs on driver behavior. Transp. Res. Rec. 1999, 53-59. [CrossRef]

16. Garber Nicholas, J.; Gadiraju, R. Impacts of differential speed limits on the speed of traffic and the rate of accidents. Transp. Res. Rec. 1995, 17-22.

17. Kockelman, K.; Bottom, J.; Kweon, J. Safety Impacts and Other Implications of Raised Speed Limits on High-Speed Roads; National Cooperative Highway Research Program (NCHRP) Report; The National Academies Press: Washington, DC, USA, 2006; pp. 17-23.

18. Pei, Y.; Cheng, G. Research on Operation Speed and Speed Limit for Freeways in China. J. Harbin Inst. Technol. 2003, 35, 168-172.

19. Cheng, G.-Z. Research on the Method of Setting Speed Limits on Freeway and Urban Expressway; Harbin University of Technology: Harbin, China, 2007.

20. Wang, L. Research on Relationship between Speed Limits and Operating Speed for Freeway; Beijing University of Technology: Beijing, China, 2011.

21. Wang, H.; Wang, W.; Chen, X.; Chen, J.; Li, J. Experimental features and characteristics of speed dispersion in urban freeway traffic. Transp. Res. Rec. 2007, 1999, 150-160. [CrossRef]

22. Transportation Research Board (TRB). Highway Capacity Manual; Special Report 87; National ResearchCouncil: Washington, DC, USA, 2000. 
23. Technical Standards for Highway Engineering (JTG B01-2014); China Standard Press: Beijing, China, 2014.

24. Leong, H.J.W. The distribution and trend of free speeds on two-lane rural highways in New South Wales. In Proceedings of the 4th Australian Road Research Board (ARRB) Conference, Melbourne, Australia, 1968; Volume 4, pp. 791-814. Available online: https://trid.trb.org/view.aspx?id=1209374 (accessed on 29 June 2019).

(C) 2019 by the authors. Licensee MDPI, Basel, Switzerland. This article is an open access article distributed under the terms and conditions of the Creative Commons Attribution (CC BY) license (http://creativecommons.org/licenses/by/4.0/). 